\title{
Anticonceptivos de Barrera
}

\author{
Dr. Germán Uriza Gutiérrez
}

Se agrupan en esta clasificación los métodos que constituyen un obstáculo mecánico que impiden al semen ponerse en contacto con la vagina o el cervix, siendo los más conocidos y usados el condón y el diafragma; o los métodos que afectan la motilidad o vitalidad del espermatozoide, como los preparados espermicidas.

Son métodos temporales de una eficacia aceptable si se siguen y se cumplen todas las condiciones para su uso correcto, pero que por ser de mucha menor cficacia que el DIU o la anticoncepción hormonal, sólo deberían ser usados por parejas con baja frecuencia coital especialmente para los jóvenes solteros con relaciones sexuales ocasionales, siempre y cuando eviten el coito en los días de mayor fertilidad. El grupo de mujeres adolescentes que por diversos motivos como la falta de maduración del eje hipotálamo hipófisis, ovarios que contraindicarían relativamente el uso de preparados hormonales, o el tamaño uterino y la nuliparidad que contraindicarían los dispositivos intrauterinos, se verían altamente beneficiadas con el uso de estos anticonceptivos de barrera que además de protegerlas contra el embarazo a esta edad las protegerían contra muchas enfermedades sexualmente transmisibles incluyendo aquí el cáncer de Cervix.

\section{HISTORIA}

Nuestra preocupación actual sobre el exceso de la población es en apariencia un acontecimiento relativamente reciente en la historia de la civilización. Sin embargo, el hombre ha tratado frecuentemente de limitar su número con el fin de evitar la inanición por superpoblación, para así proporcionar un ambiente mejor para sus hijos y preservar la salud materna.
A. Sociedad Primitiva: Aunque en tiempos primitivos existía una tasa de mortalidad natural alta, ésta se veía aumentada por el aborto, el infanticidio y el sacrificio humano con el cual se controlaba generalmente la población. Pero también el concepto de prevenir el embarazo evolucionó rápidamente y en época anterior a la escritura se utilizaban medidas como el coito prepuberal, la lactancia prolongada, el celibato o sustitutos diferentes al coito vaginal, como la masturbación, el coito oral o el coito anal.

B. Escritos Primitivos: Las recetas médicas más antiguas que se han encontrado fueron descubiertas en papiros egipcios. El "Kahun" o "Papiro Petri", que data del año 1850 A.C. describe una sustancia gomosa para bloquear el cervix y un pesario espermicida hecho de estiercol de cocodrilo. El Papiro de "Ebers" del año 1550 A.C. describe lo que debió ser el primer tapón medicinal que consistía principalmente de acacia molida, una planta que contiene goma arábiga y que al fermentarse libera ácido láctico que todavía hoy se reconoce como espermicida.

Algunos trabajos médicos hindúes escritos en sánscrito describen métodos mágicos, tapones y medicamentos vaginales de sal de roca humedecida en aceite.

C. La Grecia Clásica: En la primera mitad del siglo segundo, Sorano (98-138 D.C.), el más grande Ginecólogo de la antigüedad, escribió un tratado sobre la anticoncepción que permaneció como el más brillante y original escrito sobre el tema hasta el siglo XIX. Describe pesarios oclusivos, tapones y el uso de soluciones astringentes de varios ácidos de frutas. 
D. Roma: Los Romanos fueron los primeros en utilizar un condón elaborado con vejiga de cabro.

E. Islam en la Edad Media: Tanto Rhazes (850923), un persa, (considerado como el más importante de todos los médicos de la edad media) y Avicena de Hamadan (980-1037), detallaron una serie de métodos racionales que incluyen varios ungüentos vaginales, la oclusión vaginal y el coito interrumpido descrito en el antigüo testamento de la biblia en el versículo 9 capítulo 38 del Génesis que dice; "más sabiendo Onán que la sucesión no había de ser suya, cuando se llegaba a la mujer de su hermano dejaba caer por tierra su simiente, para no proporcionar a su hermano descendencia".

\section{F. Europa en la Edad Media y el Renacimiento:}

Seguramente los médicos europeos de la edad media conocieron los métodos anticonceptivos transmitidos por los médicos griegos, romanos y arabes. Sin embargo, sólo los utilizaron en casos rigurosamente seleccionados ya que por esta época la vida europea era dominada por la iglesia católica a la cual estaban subordinadas la ciencia y la medicina. Santo Tomás de Aquino (1225-1274), condenó la práctica de la anticoncepción como un vicio contra natura y esta prohibición se convirtió como parte integral de la doctrina católica. El mayor avance en anticoncepción por esta época en Europa, fueron los condones fabricados con intestino de cordero.

\section{OBSTACULOS MECANICOS}

\section{CONDON}

El condón es una funda de látex que se adapta al pene erecto y actúa como barrera para impedir la transmisión de espermatozoides a la vagina.

Tipos: Con reservorio en la punta o no, lubricados o no, de colores o no y lisos o rugosos.

Historia: Su origen data de muchos años. Los griegos utilizaron condones de vejiga de cordero, siendo la primera descripción escrita de un condón en 1564, cuando el anatomista italiano Fallopio afirmó que al usar una envoltura de lino sobre el pene durante la relación sexual se evitaría el contagio de enfermedades. Las primeras referencias como anticonceptivo aparecen en unos versos obscenos publicados en Inglaterra a principios del siglo XVIII. El origen de la palabra condón puede provenir del latín "condus" que quiere decir receptáculo o recipiente, a su vez derivada del persa "Kendu" o
"Kondu" que significa recipiente largo para almacenamiento.

Los primeros condones disponibles en el comercio en Europa estaban hechos de intestino de animal (cordero) y eran muy costosos; se vendían en los prostíbulos para evitar las enfermedades venéreas.

En la actualidad se fabrican principalmente de látex, aun cuando existen fabricados del ciego de oveja los cuales no se escogen ni se estiran, tienen muy buena lubricación, permiten una adaptación estrecha y adhesiva y transmiten mejor las sensaciones ya que trasmiten mejor el calor; parecen ser de buena calidad pero muy costosos, de producción limitada y desconocidos en América.

\section{Indicaciones}

1. Anticoncepción

2. Eyaculación precoz

3. Protección contra enfermedades venéreas

4. Después de vasectomías hasta la azospermia

5. En esterilidad cuando la mujer produce anticuerpos contra el esperma del compañero aglutinándolo, ya que después de usarlo durante 6 a 12 meses puede lograrse la desensibilización y conseguir el embarazo.

\section{Efectos secundarios y desventajas}

1. Alergias (casos muy raros)

2. Insatisfacción sexual por dos motivos:

a. Disminución de la sensación

b. Interrupción de las caricias para su aplicación, lo cual se puede obviar cuando la mujer coloca el condón como parte del juego amoroso.

\section{Condiciones para su uso}

1. Tener una buena provisión y guardarlos en sitio fresco.

2. Utilizar condones de buena calidad

3. No introducir el pene en la vagina sin la protección del condón.

4. Colocarlo con el pene totalmente erecto y en los no circuncidados retraer el prepucio para su colocación.

5. Desenrrollarlo en toda su extensión.

6. Si no tiene receptáculo en la punta, dejar 1 $\mathrm{cm}$ por delante del meato uretral para dar cabida al semen.

7. Si la mujer no lubrica suficientemente debe usarse lubricante adicional al que puede traer 
el condón que muchas veces no es suficiente, ya que el roce de 2 superficies secas, puede romperlo. Si no se consigue lubricante sexual puede usarse aceite mineral o aceite de bebé pero nunca vaselina porque ésta disuelve el látex.

8. Inmediatamente ocurra la eyaculación, debe extraerse el pene de la vagina antes de que el pene se ponga flácido.

9. Para sacar el pene se debe tomar el condón de la base para evitar que contracciones de los músculos vaginales y perineales por el orgasmo o por vaginismo, puedan encarcelar el condón con el semen dentro de la vagina.

\section{Efectividad}

La tasa teórica de fracaso es de 3 x 100 mujeres año y la de uso de $10 \times 100$ mujeres año.

\section{DIAFRAGMA}

Es el dispositivo vaginal de uso más común, fabricado de caucho delgado tiene forma de copa ancha, poco profunda, con el borde envuelto alrededor de un resorte semi-rígido. La tensión del resorte mantiene la forma del dispositivo y la presión que da al contorno el tono de la musculatura vaginal lo mantiene en su sitio, la parte superior detrás de la sínfisis púbica y la inferior en el fondo de saco posterior.

\section{Ventajas}

1. No interfiere directamente con el coito ya que se puede aplicar horas antes del mismo.

2. Provee lubricación adicional al coito (debe usarse con jalea).

\section{Desventajas}

1. Alta motivación por parte de la usuaria

2. Entrenamiento del personal de salud para que enseñe su uso correcto.

3. Requiere que la mujer toque sus genitales e introduzca sus dedos dentro de la vagina.

4. Requiere siempre espermicida de jalea, lo cual aumenta su costo.

5. Es relativamente difícil de insertar y colocar correctamente.

6. En raras ocasiones puede ser sentido por el hombre.

7. Algunas mujeres consideran desagradable el contacto del espermicida en sus manos.

\section{Tipos}

Los tamaños varían entre 50 y $150 \mathrm{~mm}$, la mayoría de las mujeres requieren diafragmas entre 70 y $80 \mathrm{~mm}$ de diámetro.

Para determinar la talla adecuada se realiza un tacto vaginal y se mide la distancia entre, el borde inferior de la sínfisis que se marca en el dedo índice, con el fondo de saco posterior determinado por la punta del dedo medio y así se escoge el diafragma adecuado. También se puede tomar esta medida con el juego de anillos colocándolos en la paciente en forma ascendente hasta encontrar la talla que corresponda.

\section{Condiciones de uso}

1. Se puede insertar 6 o más horas antes del coito, pero si han pasado más de dos horas de la aplicación y no se ha realizado la cópula, debe realizarse una nueva aplicación de espermicida antes de la nueva introducción.

2. Colocar espermicida por las dos caras del diafragma y en los bordes alrededor del aro.

3. Insertar el diafragma revisando el ajuste correcto, verificando:
a. Que el anillo del diafragma toca las pare- des laterales de la vagina.
b. El cuello del útero está detrás del caucho
c. El diafragma se ajusta cómodamente en- tre el fórnix vaginal posterior y la sínfisis púbica.

4. No debe retirarse el diafragma antes de 6 a 8 horas después de realizado el coito y no efectuar duchas postocoitales. Si se va a realizar otra cópula después de dos horas de la primera aplicar nuevamente espermicida. No dejarlo más de 24 horas después del coito para evitar infecciones.

5. Retirar el diafragma con el dedo índice, lavarlo con agua tibia y jabón sin esencias ni perfumes, aplicar talco sin perfume y guardarlo en sitio fresco.

\section{Contraindicaciones}

1. Prolapso uterino

2. Vagina poco tónica

3. Grandes desgarros perineales y rectocele o cistocele.

4. Fístulas

5. Severas retroversoflexiones o anteflexiones uterinas. 
6. Postparto inmediato

7. Alergia al látex o al espermicida

8. Aversión psicológica

9. Inhabilidad para aprender su uso correcto

10. Falta de personal adiestrado para realizar el ajuste inicial.

\section{Efectividad}

Tasa de falla teórica de 3 x 100 mujeres año y de uso de $17 \times 100$ mujeres año.

\section{COPA GERVICAL}

Dispositivo en forma de dedal hecho de caucho, plástico duro o metal, diseñado para colocarlo en forma muy ajustada alrededor del cervix y que se mantiene en su lugar por succión. En latinoamérica y países en desarrollo es prácticamente desconocida.

\section{Tipos}

Sus tamaños varían entre 22 y 31 milímetros y es el médico quien escoge el tamaño y realiza la primera aplicación y ajuste.

\section{Ventajas}

$\mathrm{Su}$ aplicación es relativamente independiente del coito.

\section{Desventajas}

1. Mayor dificultad para su ajuste y retiro

2. Personal adiestrado para su ajuste inicial e instrucciones sobre su uso correcto.

3. Se puede desacomodar más fácilmente que el diafragma durante el coito.

4. Secreción de mal olor cuando lleva varios días aplicado.

\section{Contraindicaciones}

1. Prolapso genital

2. Desgarro perineal y cistocele o rectoceles marcados.

3. Retroversoflexiones o anteverso - flexiones uterinas marcadas.

4. Cervicitis crónica, erosión o laceración del cervix.

\section{Efectividad}

Su tasa de falla teórica es de 3 x 100 mujeres año y de uso $8 \times 100$ mujeres año.

\section{TAPON VAGINAL}

Es históricamente uno de los dispositivos anticonceptivos más antiguos y probablemente aún se usa en muchas comunidades primitivas de todo el mundo.

\section{Tipos}

1. Tapón casero hecho con tela de algodón, seda o lana suave con un hilo atado fuertemente para retirarlo. La tela se impregna con vinagre, limón, jugo de frutas, cerveza con aspirina, aceite o jabón.

2. Esponja de mar con vinagre, tapón utilizado por Cleopatra.

3. Esponja de látex impregnada en crema o espumas espermicidas (uso comercial).

\section{Ventajas}

1. Económicas

2. Manejo fácil

3. No requiere de personal entrenado para explicar su uso.

\section{Desventajas}

1. Alta tasa de fallas

2. Alergias

3. Vaginitis por las sustancias irritantes aplicadas al tapón.

4. Shock tóxico séptico con incidencia de $10 / 100.000$ usuarias.

\section{Efectividad}

$\mathrm{Su}$ tasa de fallas es alta pero no existen estudios serios sobre su efectividad. Sin embargo, las fallas están por encima de $40 \times 100$ mujeres año. La esponja diaria de colatex impregnada con 1 gramo de nonoxinol-9 comercializada en USA y Reino Unido; tiene una tasa de fallas de $27.3 \times 100$ mujeres año.

\section{PREPARADOS ESPERMICIDAS}

Sustancias químicas u orgánicas que van a inmovilizar o destruir los espermatozoides.

\section{HISTORIA}

Los papiros Egipcios que datan de 1850 A.C. hablan de anticonceptivos vaginales hechos con miel 
y natrón (Carbonato de Sodio), o sustancias gomosas con escremento de cocodrilo o elefante. Sin embargo sólo en las postrimerías del siglo XIX los anticonceptivos vaginales pasaron del folclor al mercadeo y distribución comercial. El más conocido es un preparado de Quinina y manteca de cacao desarrollado por Walter Rendell en 1885. También se usaron el Quinosol, ácido láctico y ácido bórico en base de manteca o gelatina.

En 1937 se introdujo el acetato de Fenil Mercurio (PMA) en un producto llamado "Volpar". A principios de los sesenta la compañía EMKO introdujo la espuma cuyo principio activo es el Nonilfenoxi-polietoxi-etano (Nonoxinol 9), que también se encuentra en cremas, jaleas, óvulos y esponjas.

En los últimos años la compañía Japonesa "EISAI" introdujo la tableta espumante a base de de Eter-p-metanifenil-polioxietileno, 8,8, conocido comúnmente como TS- 88 o Menfegol y cuyo nombre comercial es Neo-sampoon. También se ha fabricado una película soluble en agua llamada CFILM y desarrollada en Hungría, la cual se ha comercializado y distribuido en países desarrollados, pero cuyos estudios sobre su efectividad han reportado resultados contradictorios. En Colombia los Laboratorios Farmacol Ltda., producen Farma 12 tabletas efervescentes a base de Aceto Fenilmercúrico y Cloruro de Benzalconio.

\section{Ventajas}

1. No necesitan prescripción

2. No requieren ajuste ni personal entrenado para su enseñanza.

3. Prácticamente inofensivos.

\section{Desventajas}

1. Alergias

2. Lubricación excesiva

3. Poco prácticos en climas cálidos por su bajo punto de fusión (ovulos).

4. Baja efectividad.

\section{BIBLIOGRAFIA}

1. IPPF “Manual de Planificación Familiar para Médicos".

2. MILLS, A. "Contracepción de Barrera". Ginecología y Obstetricia temas Actuales. Vol. 3 No. 3, 649-69, 1984.

3. POPULATION REPORTS: "Métodos de Barrera" Serie $\mathbf{H}$. Número 5, abril 1980.

4. POPULATION REPORTS: "Métodos de Barrera" Serie H. Número 7, febrero 1985.

\section{Usos y condiciones}

1. Se aplican 15 minutos antes del coito si se trata de jaleas, cremas u óvulos. En caso de espumas o tabletas espumantes se pueden aplicar 25 minutos antes de la introducción y no más de 30 minutos antes.

2. En caso de cremas, espumas o jaleas asegurarse que el aplicador está lleno antes de introducirlo en la vagina y colocarlo profundamente cerca al cervix. En caso de óvulos aplicarlos también profundos contra el cervix.

3. Si se va a repetir el coito dos horas después de la primera aplicación, se debe aplicar otra dosis.

\section{Efectividad}

En los productos modernos la efectividad no depende del principio activo, que en todos es similar, sino del vehículo en el cual va incorporado el espermicida. Un cuidadoso estudio controlado de estos métodos da una tasa de fallas para la espuma y las tabletas espumantes de 28.3 x 100 mujeres años y para las jaleas, cremas y óvulos de 38.8 x 100 mujeres año.

\section{CONCLUSION}

Los anticonceptivos de barrera son los más antiguos conocidos. Son los más económicos y los de menos efectos secundarios, pero al mismo tiempo son los menos efectivos, por lo tanto deben ser utilizados sólo por parejas con una baja frecuencia coital y en lo posible usándolos combinados, evitando la relación sexual en los días de mayor fertilidad. Son los únicos verdaderos protectores contra las enfermedades sexualmente transmisibles incluyendo el cáncer del Cervix y el SIDA.

En Colombia su compra se ha facilitado con los dispensadores colocados en algunos supermercados, pero la prohibición de la propaganda por televisión sólo se explica por el tabú y las actitudes represivas que todavía en nuestra sociedad se aplica a todos los temas relacionados con el sexo.

5. PORTER, CEDRIC, WIFE, R.; HOLTROP H.: “The Health. Provider's Guide to contraception" International Edition. The Pathfinder Fund 1983.

6. REPRODUCCION HUMANA: Federación Internacional de Ginecología y Obstetricia. Londrés y consejo de población Nueva York. vol. 3.

7. TECNOLOGIA ANTICONCEPTIVA: Facultad de Medicina Universidad de Emory. Atlanta, Georgia.

8. URIZA, G. "Manual de anticoncepción". Monografías de la Corporación Centro Regional de la Población, Bogotá, vol. 17 enero de 1982. 